\title{
The Multiple Effects of Precursors on the Properties of Polymeric Carbon Nitride
}

\author{
Wendong Zhang, ${ }^{1}$ Qin Zhang, ${ }^{1}$ Fan Dong, ${ }^{2}$ and Zaiwang Zhao ${ }^{2}$ \\ ${ }^{1}$ College of Urban Construction and Environmental Engineering, \\ Chongqing University, Chongqing 400045, China \\ ${ }^{2}$ Chongqing Key Laboratory of Catalysis and Functional Organic Molecules, College of Environmental and Biological Engineering, \\ Chongqing Technology and Business University, Chongqing 400067, China
}

Correspondence should be addressed to Fan Dong; dfctbu@126.com

Received 21 May 2013; Accepted 18 July 2013

Academic Editor: Pengyi Zhang

Copyright (C) 2013 Wendong Zhang et al. This is an open access article distributed under the Creative Commons Attribution License, which permits unrestricted use, distribution, and reproduction in any medium, provided the original work is properly cited.

\begin{abstract}
Polymeric graphitic carbon nitride $\left(\mathrm{g}-\mathrm{C}_{3} \mathrm{~N}_{4}\right)$ materials were prepared by direct pyrolysis of thiourea, dicyandiamide, melamine, and urea under the same conditions, respectively. In order to investigate the effects of precursors on the intrinsic physicochemical properties of $\mathrm{g}-\mathrm{C}_{3} \mathrm{~N}_{4}$, a variety of characterization tools were employed to analyze the samples. The photocatalytic activity of the samples was evaluated by the removal of NO in gas phase under visible light irradiation. The results showed that the as-prepared CN$\mathrm{T}$ (from thiourea), CN-D (from dicyandiamide), CN-M (from melamine), and CN-U (from urea) exhibited significantly different morphologies and microstructures. The band gaps of CN-T, CN-D, CN-M, and CN-U were 2.51, 2.58, 2.56, and $2.88 \mathrm{eV}$, respectively. Both thermal stability and yield are in the following order: CN-M $>\mathrm{CN}-\mathrm{D}>\mathrm{CN}-\mathrm{T}>\mathrm{CN}-\mathrm{U}$. The photoactivity of $\mathrm{CN}-\mathrm{U}(31.9 \%)$ is higher than that of CN-T (29.6\%), CN-D (22.2\%), and CN-M (26.8\%). Considering the cost, toxicity, and yield of the precursors and the properties of $g-\mathrm{C}_{3} \mathrm{~N}_{4}$, the best precursor for preparation of $\mathrm{g}-\mathrm{C}_{3} \mathrm{~N}_{4}$ was melamine. The present work could provide new insights into the selection of suitable precursor for $\mathrm{g}-\mathrm{C}_{3} \mathrm{~N}_{4}$ synthesis and in-depth understanding of the microstructure-dependent photocatalytic activity of g- $\mathrm{C}_{3} \mathrm{~N}_{4}$.
\end{abstract}

\section{Introduction}

Visible-light-active photocatalysts are attracting increasing interests for their potential application in the areas of environmental protection, material science, and solar energy conversion by directly utilizing nature sunlight and artificial indoor illumination [1-3]. During the past few decades, many efforts have been devoted to develop novel and efficient visible light photocatalytic systems, including inorganic photocataylsts (e.g., $\mathrm{Fe}_{2} \mathrm{O}_{3},(\mathrm{BiO})_{2} \mathrm{CO}_{3}, \mathrm{Cu}_{2} \mathrm{SnS}_{3}, \mathrm{SrTiO}_{3}$, and $\mathrm{WO}_{3} / \mathrm{BiOCl}$ ) [4-7], organic photocataylsts (e.g., graphitic carbon nitride, $\mathrm{g}-\mathrm{C}_{3} \mathrm{~N}_{4}$ ), and elemental photocataylsts (e.g., $\mathrm{Si}, \mathrm{P}, \mathrm{S}$, and $\mathrm{Se}$ ) [8-10].

In particular, g- $\mathrm{C}_{3} \mathrm{~N}_{4}$ material as a novel mental-free organic photocatalyst has triggered great attention in the fundamental and applied scientific researches due to its suitable electronic band structure, nontoxic nature, biocompatibility, high thermal and chemical stability, easily available at low cost, and amenability to chemical modification [11-16]. Properties mentioned previously make it a promising organic photocatalyst for solar energy converting, organic photosynthesis, drug delivery, and environment remediation under visible light irradiation [17-19].

g- $\mathrm{C}_{3} \mathrm{~N}_{4}$ can be prepared by the direct pyrolysis of various organic precursors. Dong et al. prepared g- $\mathrm{C}_{3} \mathrm{~N}_{4}$ from thiourea and urea at $550^{\circ} \mathrm{C}$ for $2 \mathrm{~h}[20,21]$, respectively. Yan et al. obtained g- $\mathrm{C}_{3} \mathrm{~N}_{4}$ from melamine at $550^{\circ} \mathrm{C}$ for $4 \mathrm{~h} \mathrm{[22].} \mathrm{Xu}$ et al. prepared $\mathrm{g}-\mathrm{C}_{3} \mathrm{~N}_{4}$ by directly heating dicyandiamide first at $350^{\circ} \mathrm{C}$ for $2 \mathrm{~h}$ and then $550^{\circ} \mathrm{C}$ for another $2 \mathrm{~h}$ [23], respectively. The different pyrolysis conditions for $\mathrm{g}-\mathrm{C}_{3} \mathrm{~N}_{4}$ synthesis made the comparison of the precursors difficult. Until now, little information is known about the effects of precursors on intrinsic physicochemical properties of g- $\mathrm{C}_{3} \mathrm{~N}_{4}$ under the same pyrolysis conditions, including morphology, band gap, 
TABLE 1: The cost, acute toxicity, and melting point of thiourea, dicyandiamide, melamine, and urea [16].

\begin{tabular}{lccc}
\hline Precursors & Cost $(\$ / \mathrm{t})$ & $\begin{array}{c}\text { Acute toxicity } \\
\mathrm{LD}_{50} \text { (oral, rat) }\end{array}$ & $\begin{array}{c}\text { Melting point } \\
\left({ }^{\circ} \mathrm{C}\right)\end{array}$ \\
\hline Thiourea & 3906 & $125 \mathrm{mg} / \mathrm{kg}$ & 182 \\
Dicyandiamide & 1538 & $4000 \mathrm{mg} / \mathrm{kg}$ & 209 \\
Melamine & 2025 & $3248 \mathrm{mg} / \mathrm{kg}$ & 345 \\
Urea & 450 & $8500 \mathrm{mg} / \mathrm{kg}$ & 133 \\
\hline
\end{tabular}

thermal stability, surface area, pore volume, and yield and visible light photocatalytic activity. It is thus highly desirable to solve this issue in order to screen the most suitable precursors for synthesis of $\mathrm{g}-\mathrm{C}_{3} \mathrm{~N}_{4}$.

In this paper, $g-\mathrm{C}_{3} \mathrm{~N}_{4}$ materials were prepared by directly treating thiourea, dicyandiamide, melamine, and urea under the same condition $\left(550^{\circ} \mathrm{C}\right.$ for $3 \mathrm{~h}$ in air), respectively. The precursors are easily available in the chemical industry at low cost (see Table 1). Various characterization tools were utilized to analyze the effects of precursors on the intrinsic physicochemical properties and photocatalytic activity of $\mathrm{g}-\mathrm{C}_{3} \mathrm{~N}_{4}$. The results showed that the precursors had significant effect on the properties of $\mathrm{g}-\mathrm{C}_{3} \mathrm{~N}_{4}$. Considering the cost, toxicity, and yield of the precursors and the properties of $g-\mathrm{C}_{3} \mathrm{~N}_{4}$, the best precursor was confirmed.

\section{Experimental}

2.1. Synthesis of $g-C_{3} N_{4}$. In a typical synthesis, $12 \mathrm{~g}$ of thiourea was put into a semiclosed alumina crucible with a cover and then heated to $550^{\circ} \mathrm{C}$ in a muffle furnace for $3 \mathrm{~h}$ at a heating rate of $10^{\circ} \mathrm{C} \mathrm{min}^{-1}$. Following the same procedure, g- $\mathrm{C}_{3} \mathrm{~N}_{4}$ samples were prepared by directly treating dicyandiamide, melamine, and urea, respectively. After the reaction, the alumina crucible was cooled to room temperature. The resultant g- $\mathrm{C}_{3} \mathrm{~N}_{4}$ were collected and ground into powder, respectively. The different $\mathrm{g}-\mathrm{C}_{3} \mathrm{~N}_{4}$ prepared from thiourea, dicyandiamide, melamine, and urea were labeled as CN-T, CN-D, CN$\mathrm{M}$, and $\mathrm{CN}-\mathrm{U}$, respectively.

2.2. Characterization. The crystal phases of the samples were analyzed by X-ray diffraction with $\mathrm{Cu} K \alpha$ radiation (XRD: model D/max RA, Rigaku Co., Japan). FT-IR spectra were recorded on a Nicolet Nexus spectrometer on samples embedded in $\mathrm{KBr}$ pellets. The morphology and structure of the samples were further examined by transmission electron microscopy (TEM: JEM-2010, Japan). The UV-vis diffuse reflection spectra were obtained for the dry-pressed disk samples using a Scan UV-vis spectrophotometer (UV-vis DRS: UV-2450, Shimadzu, Japan) equipped with an integrating sphere assembly, using $\mathrm{BaSO}_{4}$ as the reflectance sample. Nitrogen adsorption-desorption was conducted on a nitrogen adsorption apparatus (ASAP 2020, USA). The thermal stability was detected by using thermogravimetry analysis (TG-DSC, Netsch STA 449F3) under $\mathrm{N}_{2}$ gas atmosphere. All the samples were degassed at $150^{\circ} \mathrm{C}$ prior to measurements.
2.3. Visible Light Photocatalytic Performance. The photocatalytic activity was investigated by removal of $\mathrm{NO}$ at ppb levels in a continuous flow reactor at ambient temperature. The volume of the rectangular reactor, which was made of polymethyl methacrylate plastics and covered with quartz-glass, was $4.5 \mathrm{~L}(30 \mathrm{~cm} \times 15 \mathrm{~cm} \times 10 \mathrm{~cm})$. A $100 \mathrm{~W}$ commercial tungsten halogen lamp (General Electric) was vertically placed outside and above the reactor. Four minifans were used to cool the flow system. Adequate distance was also kept from the lamp to the reactor for the same purpose to keep the temperature at a constant level. For the visible light photocatalytic activity test experiment, a UV cut-off filter (420 nm) was adopted to remove UV light in the light beam.

For each photocatalytic activity test, two sample dishes (with a diameter of $12.0 \mathrm{~cm}$ ) containing photocatalyst powder were placed in the center of the reactor. The weight of the photocatalyst used for each dish was kept at $0.1 \mathrm{~g}$. g- $\mathrm{C}_{3} \mathrm{~N}_{4}$ sample was added into $30 \mathrm{~mL}$ of $\mathrm{H}_{2} \mathrm{O}$ and sonicated for $10 \mathrm{~min}$, and then photocatalyst samples were prepared by coating aqueous suspension of the samples onto the glass dishes. The coated dish was pretreated at $60^{\circ} \mathrm{C}$ to remove water in the suspension and then cooled to room temperature before photocatalytic testing.

The NO gas was acquired from a compressed gas cylinder at a concentration of $100 \mathrm{ppm}$ of $\mathrm{NO}\left(\mathrm{N}_{2}\right.$ balance, BOC gas) with the National Institute of Standards and Technology (NIST) standard. The initial concentration of NO was diluted to about $600 \mathrm{ppb}$ by the air stream supplied by a zero air generator (Thermo Environmental Inc., model 111). The relative humidity at indoor environmental condition is $40 \%-80 \%$. The desired relative humidity in the present system is controlled at $50 \%$ in the gas flow which could simulate the indoor environmental conditions. The desired relative humidity (RH) level of the NO flow was controlled at $50 \%$ by passing the zero air streams through a humidification chamber. The gas streams were premixed completely by a gas blender, and the flow rate was controlled at $2.4 \mathrm{~L} \mathrm{~min}^{-1}$ by a mass flow controller. After the adsorption-desorption equilibrium was achieved, the lamp was turned on. The concentration of NO was continuously measured by a chemiluminescence NO analyzer (Thermo Environmental Instruments Inc., model 42c), which monitors $\mathrm{NO}, \mathrm{NO}_{2}$, and $\mathrm{NOx}$ ( $\mathrm{NOx}$ represents $\mathrm{NO}+\mathrm{NO}_{2}$ ) with a sampling rate of $0.7 \mathrm{~L} \mathrm{~min}^{-1}$. The removal ratio $(\eta)$ of $\mathrm{NO}$ was calculated as $\eta(\%)=\left(1-C / C_{0}\right) \times 100 \%$, where $C$ and $C_{0}$ are concentrations of NO in the outlet steam and the feeding stream, respectively. The kinetics of photocatalytic NO removal reaction is a pseudofirst order reaction at low NO concentration as $\ln \left(C_{0} / C\right)=k t$, where $k$ is the apparent rate constant.

\section{Result and Discussion}

The XRD patterns (Figure 1(a)) of the samples prepared from thiourea, dicyandiamide, melamine, and urea can be indexed to $g-\mathrm{C}_{3} \mathrm{~N}_{4}$ [24-26]. The strongest interplanar stacking peaks of the conjugated aromatic systems at around $27.6^{\circ}$ are indexed to graphitic materials as the (002) peak. The small angle peaks at around $13.0^{\circ}$ can be indexed to (100) peak 


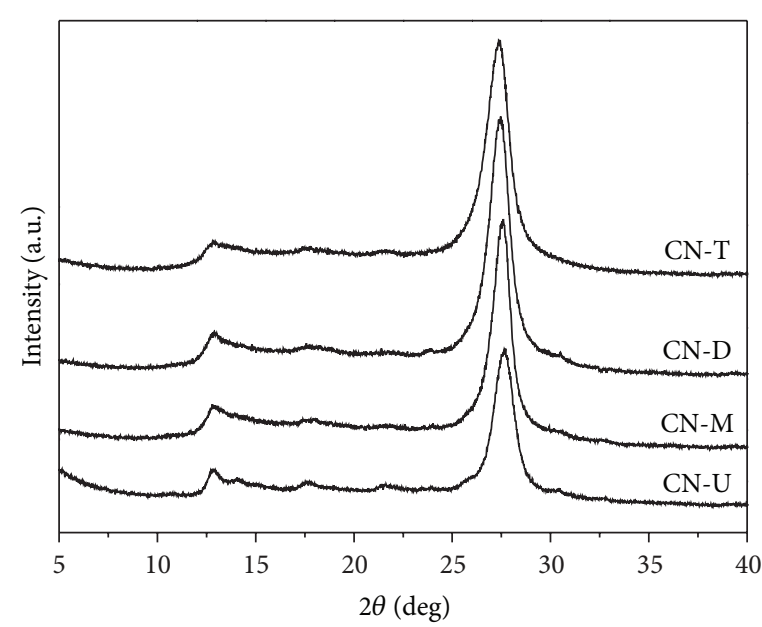

(a)

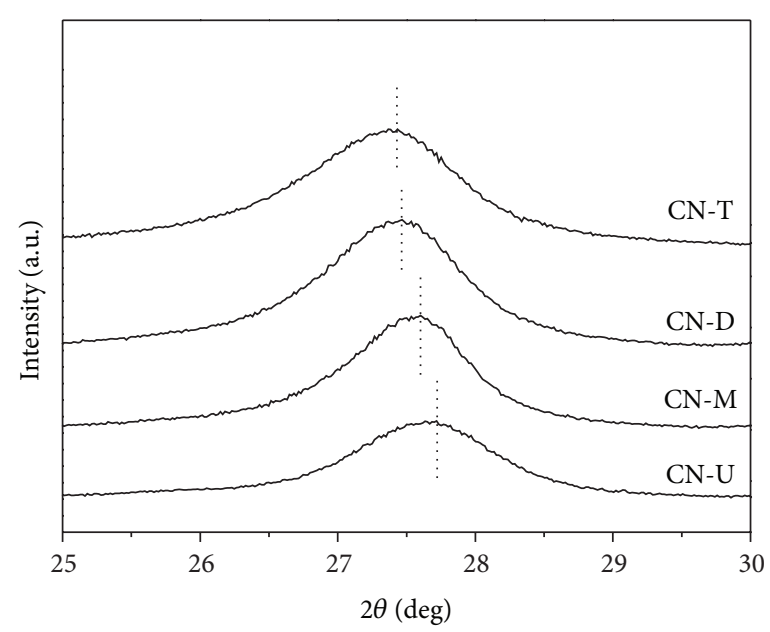

(b)

FIGURE 1: XRD patterns of the CN-T, CN-D, CN-M, and CN-U (a) and enlarged view of the (002) peak (b).

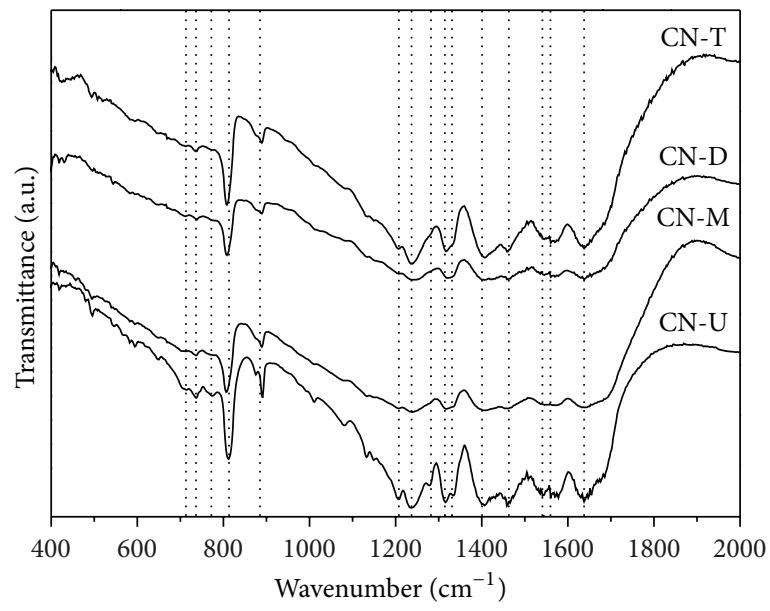

(a)

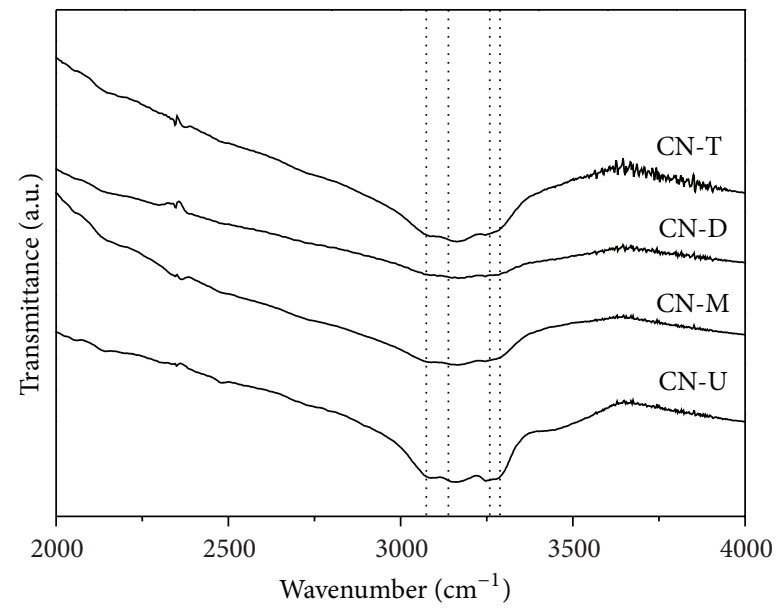

(b)

Figure 2: FT-IR spectra for CN-T, CN-D, CN-M, and CN-U.

of graphitic materials, corresponding to the in-plane tri-striazine units which formed one-dimensional (1D) melon strands. Further observation implies (Figure 1(b)) that the typical (002) peak is $27.43^{\circ}$ for CN-T, $27.47^{\circ}$ for CN-D, $27.60^{\circ}$ for $\mathrm{CN}-\mathrm{M}$, and $27.72^{\circ}$ for $\mathrm{CN}-\mathrm{U}$, respectively, indicating that the interplanar distance tends to decrease and g- $\mathrm{C}_{3} \mathrm{~N}_{4}$ structure becomes more compact. The dense structure can be ascribed to the localization of the electrons and stronger binding between the layers $[27,28]$. The dominant $(002)$ diffraction peaks shifted toward higher diffraction angles for $\mathrm{CN}-\mathrm{U}$ compared with $\mathrm{CN}-\mathrm{T}$, indicating that O-containing precursors (urea) could improve the polycondensation of g- $\mathrm{C}_{3} \mathrm{~N}_{4}$. In addition, the intensity and breadth of the XRD patterns (Figure 1) are different, due to the presence of different nanostructures and morphologies of the as-prepared g- $\mathrm{C}_{3} \mathrm{~N}_{4}$ [29].

The chemical structures of dicyandiamide and melamine containa $\mathrm{C}=\mathrm{N}$ bond which plays a key role in the formation of $\mathrm{g}_{-} \mathrm{C}_{3} \mathrm{~N}_{4}$. However, both the S-containing thiourea and
O-containing urea do not containa $\mathrm{C}=\mathrm{N}$ bond. The fact indicates that the formation mechanisms and condensation degrees of thiourea and urea are different from that of dicyandiamide and melamine [20-22,30].

Figure 2(a) shows that the weak absorption at the 700$800 \mathrm{~cm}^{-1}$ region is assigned to the bending vibration mode of $\mathrm{CN}$ heterocycles and the characteristic out of plane bending vibration mode of the triazine units at $810 \mathrm{~cm}^{-1}$ for all the samples [31]. All the samples reveal several bands in the 1200$1650 \mathrm{~cm}^{-1}$ region, which corresponds to the typical stretching vibration modes of the heptazine heterocyclic ring $\left(\mathrm{C}_{6} \mathrm{~N}_{7}\right)$ units [32].

The stretching vibration modes of $\mathrm{N}-\mathrm{H}$ and $\mathrm{O}-\mathrm{H}$ at $3000-3500 \mathrm{~cm}^{-1}$ are also observed (Figure 2(b)), indicating the existence of uncondensed amino groups and absorbed $\mathrm{H}_{2} \mathrm{O}$ molecules in all the samples [33]. It can be seen that the peak intensity of $\mathrm{CN}-\mathrm{U}$ at $400-4000 \mathrm{~cm}^{-1}$ is stronger than that of CN-T, $\mathrm{CN}-\mathrm{D}$, and $\mathrm{CN}-\mathrm{M}$, indicating that $\mathrm{O}$-containing 


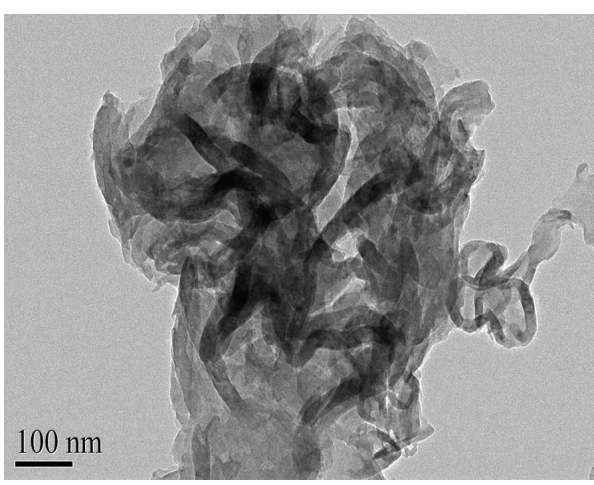

(a)

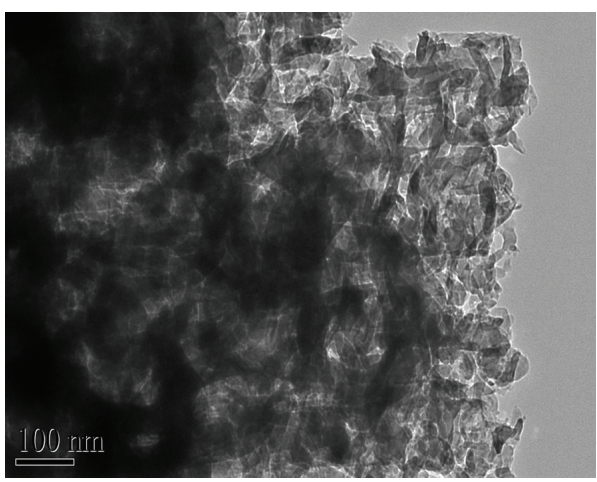

(c)

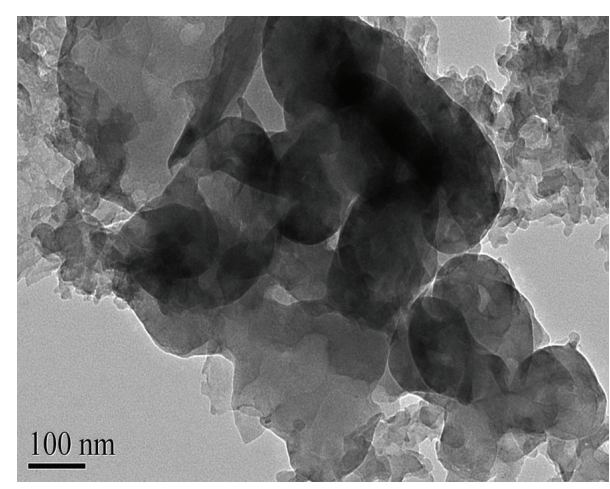

(b)

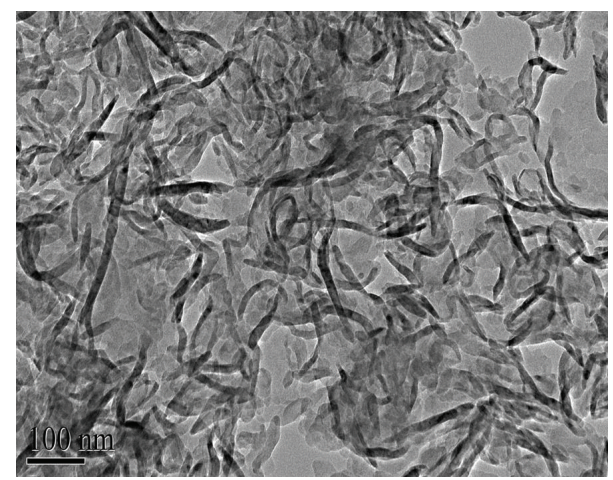

(d)

Figure 3: TEM images of CN-T (a), CN-D (b), CN-M (c), and CN-U (d).

precursors could improve the polycondensation of $\mathrm{g}-\mathrm{C}_{3} \mathrm{~N}_{4}$ [34].

The morphologies and microstructures of CN-T, CN-D, $\mathrm{CN}-\mathrm{M}$, and $\mathrm{CN}-\mathrm{U}$ were observed by TEM. As shown in Figure 3, all the samples consist of large amounts of packing layers with different sizes of nanosheets and nanoparticles, which exhibit obviously wrinkles and irregular shapes. Figure 3(a) shows that CN-T is composed of smooth and flat layers. Numerous large buckle nanosheets with aggregated structures which formed smooth layers in the CN-D sample can be seen in Figure 3(b). By observing carefully for CN-M (Figure 3(c)), the layers consist of dense and thick nanosheets with irregular shape. Figure 3(d) shows that $\mathrm{CN}$ $\mathrm{U}$ is composed of smooth and thin layers with typical porous morphology and loose structure. The result clearly shows that $\mathrm{CN}-\mathrm{U}$ prepared from urea favors the formation of typical porous structure. The fact indicates that the morphologies and microstructures of the resultant g- $\mathrm{C}_{3} \mathrm{~N}_{4}$ strongly depend on the different heteroatom-containing precursors.

As shown in Figure 4(a), all the samples exhibit excellent visible light absorption, and the absorption edges of the samples shift apparently to longer wavelengths from $\mathrm{CN}-\mathrm{U}$ to CN-T. The band energies $\left(E_{g}\right)$ which can be estimated from the intercept of the tangents to the plots of $(A h \nu)^{1 / 2}$ versus photo energy (Figure 4(b)) are 2.51, 2.58, 2.56, and $2.88 \mathrm{eV}$ for CN-T, CN-D, CN-M, and CN-U, respectively. The fact indicates that the precursors could affect the band gap and absorption edge of g- $\mathrm{C}_{3} \mathrm{~N}_{4}$, which may be caused by the different local structures, defects, and degrees of condensation during the pyrolysis $[8,11]$.

Figure 5 shows the nitrogen adsorption-desorption isotherms and corresponding curves of the pore size distribution for CN-T, CN-D, CN-M, and CN-U. The isotherms of CN-T (Figure 5(a)), CN-D (Figure 5(c)), and CN-M (Figure 5(e)) can be classified to type IV, which indicates the presence of mesopores. The CN-U exhibits type III behavior (Figure 5(g)), which can be ascribed to the weak adsorbent-adsorbent interaction [35]. The specific surface areas and pore volumes of CN-T $\left(23 \mathrm{~m}^{2} / \mathrm{g}\right.$ and $\left.0.14 \mathrm{~cm}^{3} / \mathrm{g}\right)$ and $\mathrm{CN}-\mathrm{U}\left(153 \mathrm{~m}^{2} / \mathrm{g}\right.$ and $\left.0.40 \mathrm{~cm}^{3} / \mathrm{g}\right)$ are significantly higher than that of CN-D $\left(18 \mathrm{~m}^{2} / \mathrm{g}\right.$ and $\left.0.09 \mathrm{~cm}^{3} / \mathrm{g}\right)$ and CN-M $\left(14 \mathrm{~m}^{2} / \mathrm{g}\right.$ and $\left.0.06 \mathrm{~cm}^{3} / \mathrm{g}\right)$. The data illustrates that the heteroatoms of sulfur and oxygen play a key role in increasing the specific surface area and enlarging the pore volume during the condensation. The formation of $\mathrm{H}_{2} \mathrm{~S}$ and $\mathrm{CO}_{2}$, release of $\mathrm{NH}_{3}$, and generation of additional $\mathrm{H}_{2} \mathrm{O}$ vapor during the pyrolysis of thiourea and urea favor the expansion of the packing layers and porous structure $[32,35]$. Further observation implies that all the samples have micropores and mesopores. The interconnected porous network could mainly contribute to the formation of micropores and mesopores of CN-T (Figure 5(b)) and CN-U (Figure 5(h)), the aggregation of nanosheets and nanoparticles could result in the formation of the micropores and mesopores of CN-D (Figure 5(d)) and CN-M (Figure 5(f)) [19, 20]. 


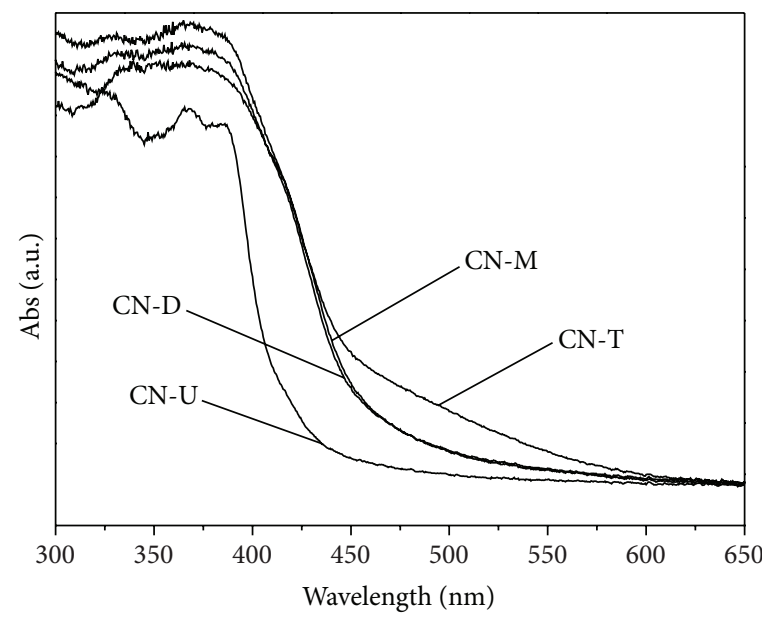

(a)

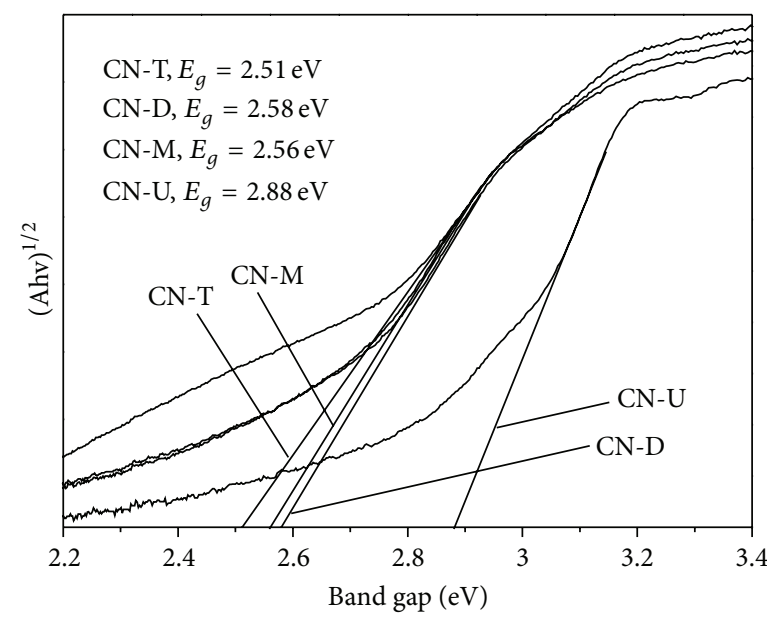

(b)

FIgURE 4: UV-vis DRS (a) and plots of $(A h \nu)^{1 / 2}$ versus photo energy (b) of CN-T, CN-D, CN-M, and CN-U.

TABLE 2: The $S_{\mathrm{BET}}$, pore volume, band gap, removal ration, initial rate constant $k$, yield, and thermal stability of CN-T, CN-D, CN-M, and CN-U.

\begin{tabular}{lccccccc}
\hline Samples & $S_{\text {BET }}\left(\mathrm{m}^{2} / \mathrm{g}\right)$ & $\begin{array}{c}\text { Pore volume } \\
\left(\mathrm{cm}^{3} / \mathrm{g}\right)\end{array}$ & Band gap $(\mathrm{eV})$ & $\begin{array}{c}\text { Removal ratio } \\
\eta(\%)\end{array}$ & $k\left(\mathrm{~min}^{-1}\right)$ & $\begin{array}{c}\text { Yield }(\mathrm{g}) \\
\text { stability }\left({ }^{\circ} \mathrm{C}\right)\end{array}$ \\
\hline $\mathrm{CN}-\mathrm{T}$ & 23 & 0.14 & 2.51 & 29.6 & 0.310 & 1.46 & $<550^{\circ} \mathrm{C}$ \\
$\mathrm{CN}-\mathrm{D}$ & 18 & 0.09 & 2.58 & 22.2 & 0.079 & 3.73 & $<563^{\circ} \mathrm{C}$ \\
$\mathrm{CN}-\mathrm{M}$ & 14 & 0.06 & 2.56 & 26.8 & 0.298 & 5.32 & $<575^{\circ} \mathrm{C}$ \\
$\mathrm{CN}-\mathrm{U}$ & 153 & 0.40 & 2.88 & 31.9 & 0.384 & 0.12 & $<530^{\circ} \mathrm{C}$ \\
\hline
\end{tabular}

In order to understand the thermal stability of CN-T, CN$\mathrm{D}, \mathrm{CN}-\mathrm{M}$, and $\mathrm{CN}-\mathrm{U}$, the thermal analysis was carried out by using TG-DSC and the heating rate of $20^{\circ} \mathrm{C} / \mathrm{min}$ under $\mathrm{N}_{2}$ gas atmosphere. It can be found that the CN-T (Figure 6(a)), CN-D (Figure 6(b)), and CN-M (Figure 6(c)) became unstable when the heating temperature was above 550,563, and $575^{\circ} \mathrm{C}$, respectively. The exothermic peaks can be seen at 672.4 for $\mathrm{CN}-\mathrm{T}, 683.1$ for $\mathrm{CN}-\mathrm{D}$, and $649.5^{\circ} \mathrm{C}$ for $\mathrm{CN}-\mathrm{U}$, which should be attributed to the decomposition for the samples. Figure 6(d) shows that no significant weight loss of $\mathrm{CN}-\mathrm{U}$ is recorded when the temperature is below $530^{\circ} \mathrm{C}$, and complete decomposition of $\mathrm{CN}-\mathrm{U}$ occurred at $750^{\circ} \mathrm{C}$. Further observation reveals that there are two strong exothermic peaks at 550.1 and $682.4^{\circ} \mathrm{C}$ of $\mathrm{CN}-\mathrm{U}$, which can be ascribed to the sublimation and thermal decomposition [36], respectively. It should be noted that the thermal stability of the samples is different, due to the different degrees of condensation and the packing between the layers during the polymerization $[37,38]$.

The photocatalytic performance of the as-prepared samples was further evaluated by removal of NO in gas phase in order to demonstrate their potential ability for indoor air purification under visible light irradiation at room temperature (Figure 7). There are four reactions of the photocatalytic materials, which involved that NO reacted with the photo-generated reactive radicals and produced $\mathrm{HNO}_{2}$ and $\mathrm{HNO}_{3}$ displayed in the following [39]:

$$
\begin{gathered}
\mathrm{NO}+2^{\circ} \mathrm{OH} \longrightarrow \mathrm{NO}_{2}+\mathrm{H}_{2} \mathrm{O} \\
\mathrm{NO}_{2}+{ }^{\circ} \mathrm{OH} \longrightarrow \mathrm{NO}_{3}{ }^{-}+\mathrm{H}^{+} \\
\mathrm{NO}+\mathrm{NO}_{2}+\mathrm{H}_{2} \mathrm{O} \longrightarrow 2 \mathrm{HNO}_{2} \\
\mathrm{NO}+{ }^{\cdot} \mathrm{O}_{2}{ }^{-} \longrightarrow \mathrm{NO}_{3}{ }^{-}
\end{gathered}
$$

Figure 7 (a) shows the variation of $\mathrm{NO}$ concentration $\left(C / C_{0} \%\right)$ with irradiation time over the samples under visible light irradiation $(\lambda>420 \mathrm{~nm})$. Here, $C_{0}$ is the initial concentration of $\mathrm{NO}$, and $C$ is the concentration of $\mathrm{NO}$ after photocatalytic reaction for time $t$.

As shown in Figure 7(a), the concentration of NO for all samples decreased rapidly due to the photocatalytic degradation in $5 \mathrm{~min}$. However, the reaction intermediates, and final products generated during irradiation may occupy the active sites of photocatalyst, which result in the decrease in activity. After $40 \mathrm{~min}$ irradiation, the removal rates and apparent rate constants of CN-T $\left(29.2 \%\right.$ and $\left.0.310 \mathrm{~min}^{-1}\right)$ and $\mathrm{CN}-\mathrm{U}\left(32.2 \%\right.$ and $\left.0.384 \mathrm{~min}^{-1}\right)$ are higher than that of CN-D (22.2\% and $\left.0.079 \mathrm{~min}^{-1}\right)$ and CN-M (26.2\% and 


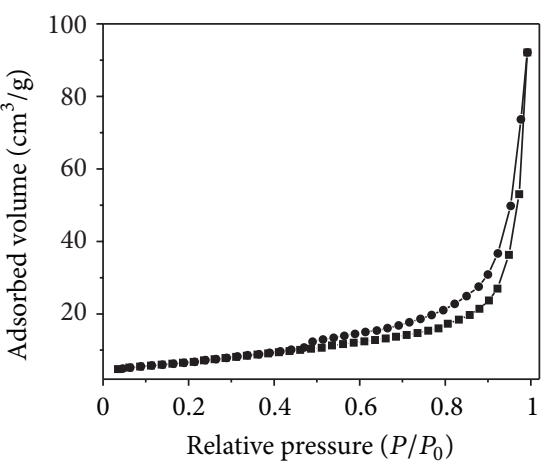

(a)

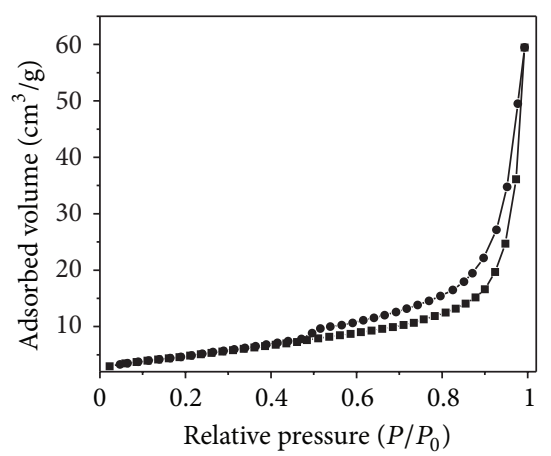

(c)

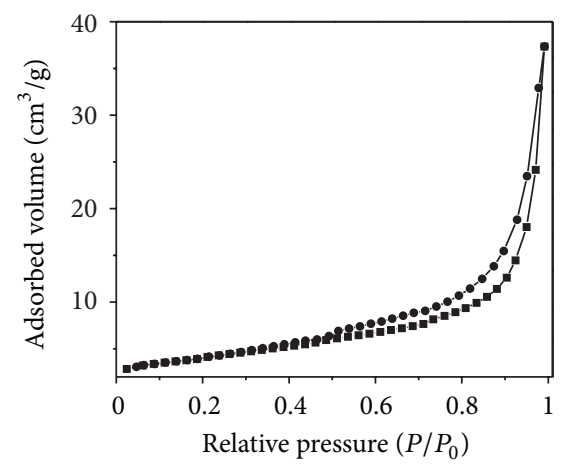

(e)

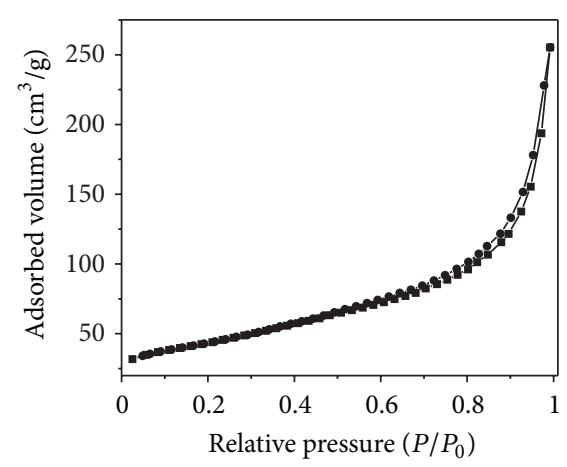

(g)

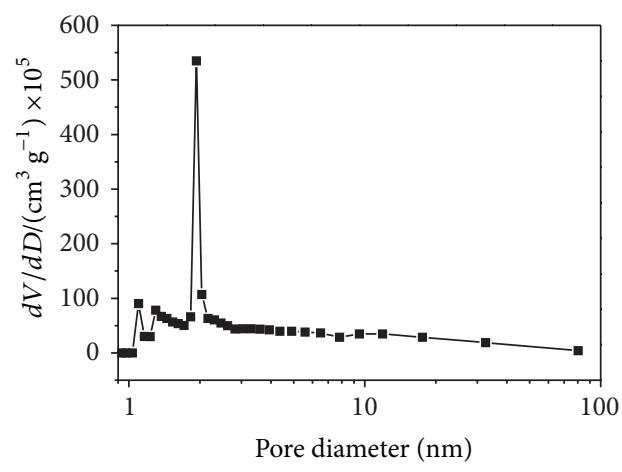

(b)

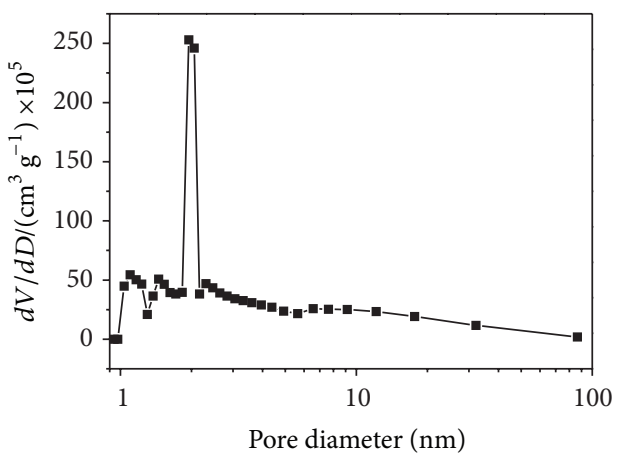

(d)

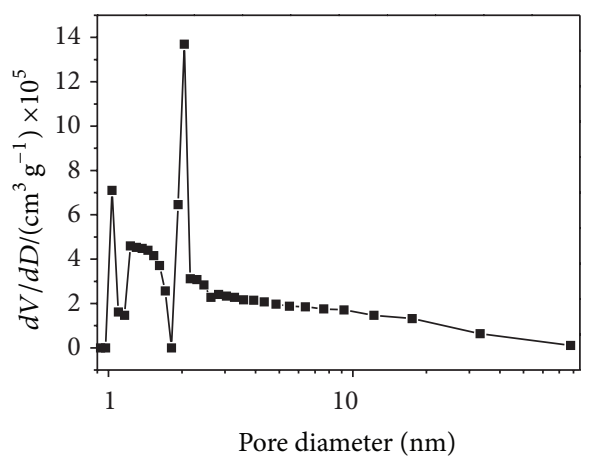

(f)

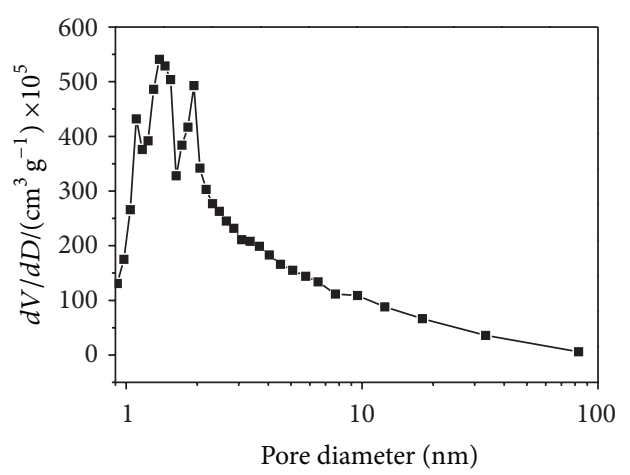

(h)

FIGURE 5: $\mathrm{N}_{2}$ adsorption-desorption isotherms of CN-T (a), CN-D (c), CN-M (e), and CN-U (g) and the corresponding pore size distribution curves of CN-T (b), CN-D (d), CN-M (f), and CN-U (h). 


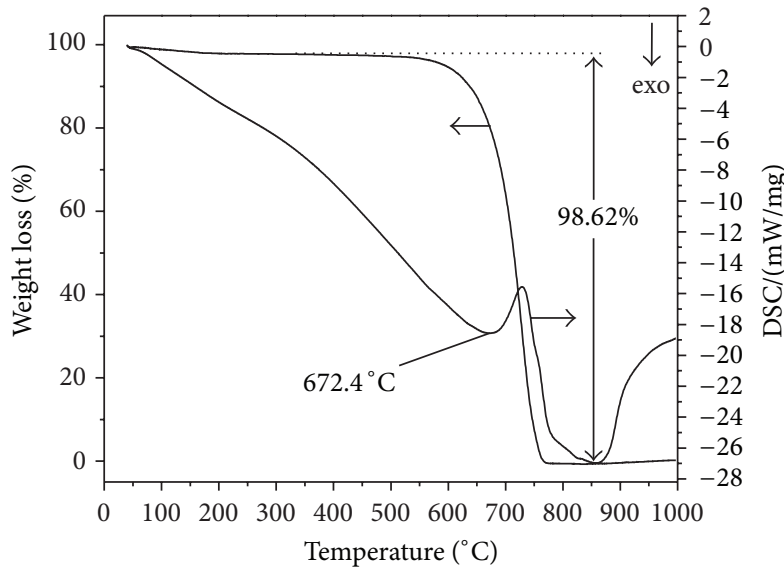

(a)

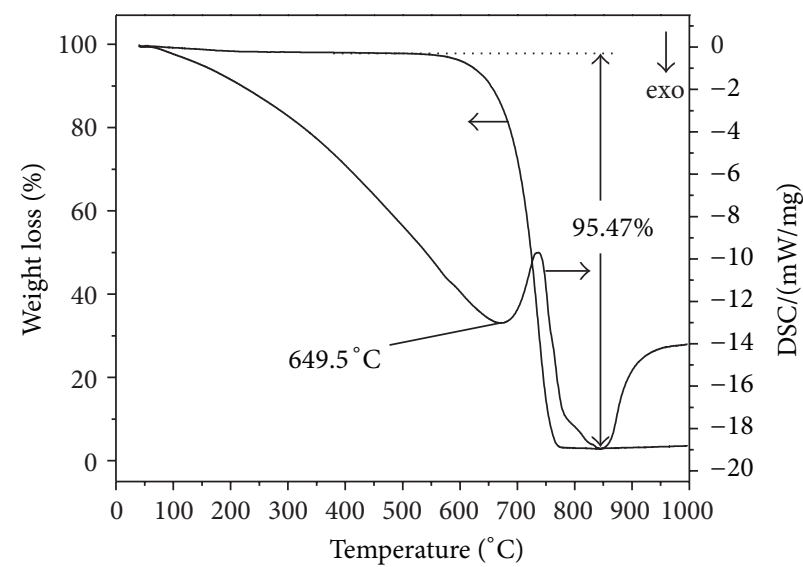

(c)

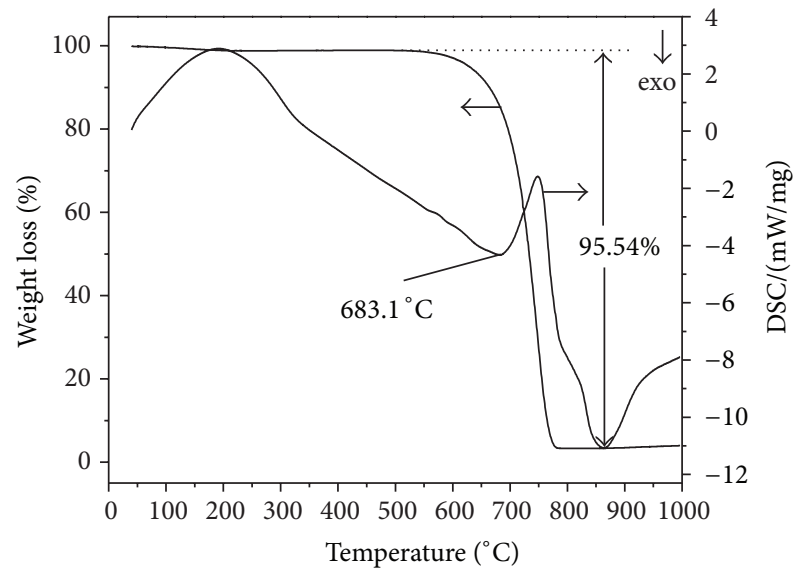

(b)

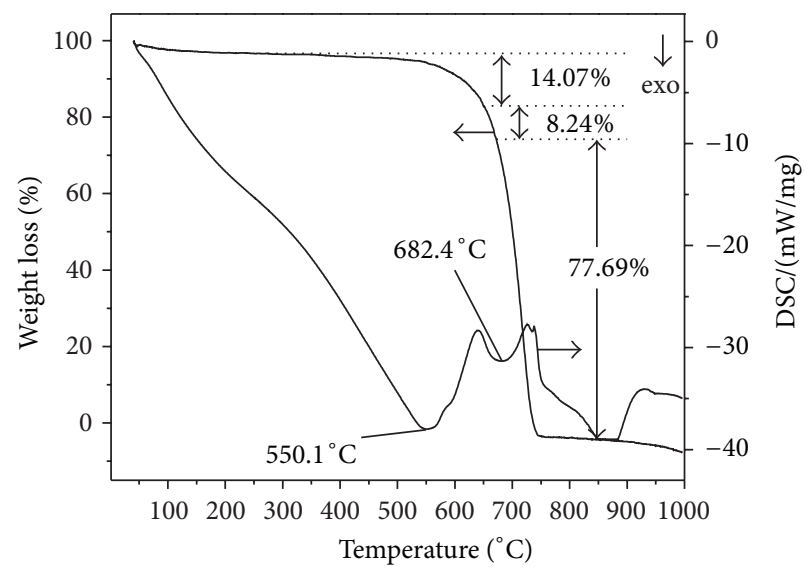

(d)

Figure 6: TG-DSC thermalgrams for CN-T (a), CN-D (b), CN-M (c), and CN-U (d).

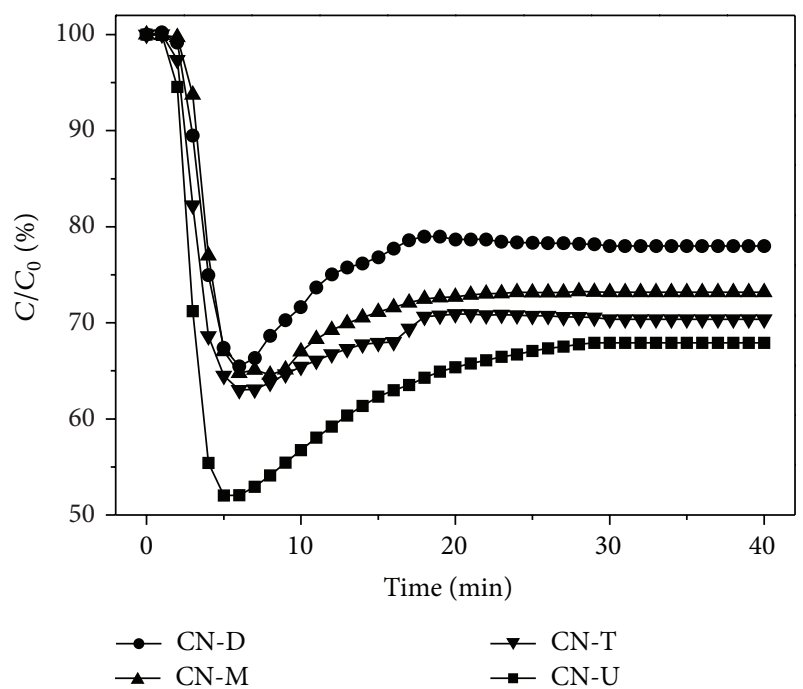

(a)

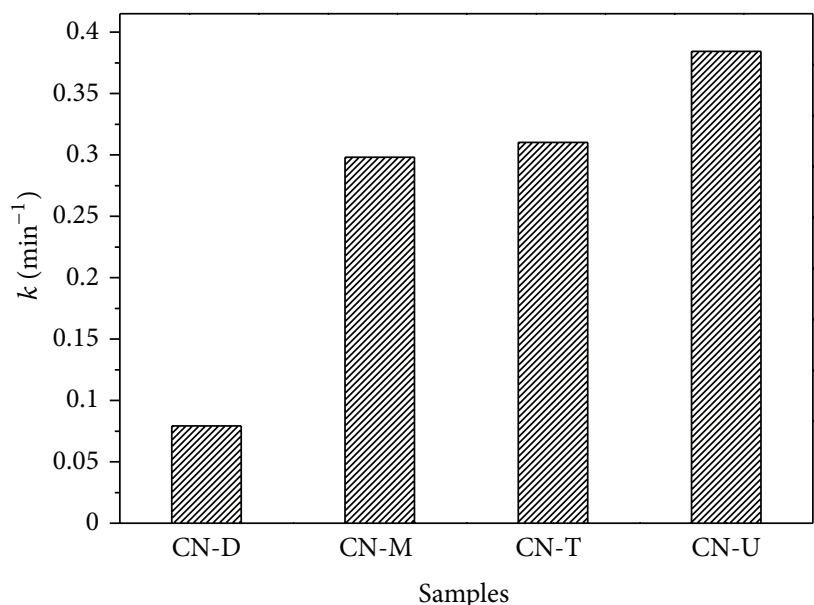

(b)

Figure 7: Photocatalytic activity (a) and initial rate constants (b) of CN-T, CN-D, CN-M, and CN-U for removal of NO under visible light irradiation $(\lambda>420 \mathrm{~nm})$ at room temperature. 
$0.298 \mathrm{~min}^{-1}$ ), respectively. Generally, CN-T, CN-D, and CN$\mathrm{M}$ with narrower band gaps than $\mathrm{CN}-\mathrm{U}$ (see Table 2) are favorable for photocatalytic reaction, due to the enhanced visible light absorption with more available photogenerated electron hole. In fact, the high surface areas and large pore volumes can enhance the adsorption of reactants and diffusion of the reaction products and provide more efficient active sites for photochemical reaction [40, 41]. Thus, the surface area and pore volume of $\mathrm{CN}-\mathrm{U}$ play a more significant role in NO degradation than the electronic properties. However, it is interesting to find that the $\mathrm{CN}$ $\mathrm{M}$ exhibits higher photocatalytic activity than that of $\mathrm{CN}$ D. Figure 4(b) shows that the band energy of CN-M is narrower than that of $\mathrm{CN}-\mathrm{D}$, which can enhance visible light absorption in $\mathrm{CN}-\mathrm{M}$ sample. On the other hand, the enhanced condensation of CN-M can effectively reduce the number of structure defects (e.g., uncondensation groups of $\mathrm{NH}_{2}$ and $-\mathrm{NH}$ ) which always capture the electrons or holes to prevent the following photoredox reaction [8]. The fact indicates that the photocatalytic efficiency strongly depends on the surface area, pore volume, band energy, and the degree of condensation of $\mathrm{g}-\mathrm{C}_{3} \mathrm{~N}_{4}$.

To ensure the large-scale application, four evaluation indicators were proposed for screening the most suitable precursors, including the cost, toxicity, and yield of the precursors and the removal rate for the contaminant. As shown in Tables 1 and 2, melamine exhibits the middle cost, toxicity, and removal ratio for the degradation of NO. However, it possesses the highest yield among the four precursors. Based on the advantages analysis previously mentioned, the best precursor is melamine.

\section{Conclusions}

In summary, g- $\mathrm{C}_{3} \mathrm{~N}_{4}$ samples were prepared by a simple pyrolysis of thiourea, dicyandiamide, melamine, and urea under the same procedures, respectively. The systematic research results confirmed that the precursors have significant effect on the morphology, band gap, surface area, pore volume, thermal stability, and visible light photocatalytic activity of $\mathrm{g}-\mathrm{C}_{3} \mathrm{~N}_{4}$. Considering the cost, toxicity, and yield of the precursors and the properties of $\mathrm{g}-\mathrm{C}_{3} \mathrm{~N}_{4}$, the best precursor for preparation of $\mathrm{g}-\mathrm{C}_{3} \mathrm{~N}_{4}$ is melamine. The present work could provide new insights into appropriate selection of precursors for $\mathrm{g}-\mathrm{C}_{3} \mathrm{~N}_{4}$ synthesis as visible light photocatalyst in environmental protection.

\section{Conflict of Interests}

The authors declare that they have no conflict of interests.

\section{Acknowledgments}

This research is financially supported by the National Natural Science Foundation of China (51108487), the National High Technology Research and Development Program (863 Program) of China (2010AA064905), the Natural Science Foundation Project of CQ CSTC (cstc2012jjA20014), and the
Critical Patented Projects in the Control and Management of the National Polluted Water Bodies (2012ZX07102-001-003).

\section{References}

[1] J. S. Zhang, J. H. Sun, K. Maeda et al., "Sulfur-mediated synthesis of carbon nitride: band-gap engineering and improved functions for photocatalysis," Energy \& Environmental Science, vol. 4, no. 3, pp. 675-678, 2011.

[2] H. Tong, S. X. Ouyang, Y. P. Bi, N. T. Umezawa, M. Oshikiri, and J. H. Ye, "Nano-photocatalytic materials: possibilities and challenges," Advanced Materials, vol. 24, no. 2, pp. 229-251, 2012.

[3] J. G. Yu, M. Jaroniec, and G. X. Lu, " $\mathrm{TiO}_{2}$ photocatalytic materials," International Journal of Photoenergy, vol. 2012, Article ID 206183, 5 pages, 2012.

[4] N. Todorova, T. Giannakopoulou, G. Romanos, T. Vaimakis, J. G. Yu, and C. Trapalis, "Preparation of fluorine-doped $\mathrm{TiO}_{2}$ photocatalysts with controlled crystalline structure," International Journal of Photoenergy, vol. 2008, Article ID 534038, 9 pages, 2008.

[5] F. Dong, W. K. Ho, S. C. Lee et al., “Template-free fabrication and growth mechanism of uniform $(\mathrm{BiO})_{2} \mathrm{CO}_{3}$ hierarchical hollow microspheres with outstanding photocatalytic activities under both UV and visible light irradiation," Journal of Materials Chemistry, vol. 21, no. 33, pp. 12428-12436, 2011.

[6] J. G. Yu, P. Y. Zhang, H. G. Yu, and C. Trapalis, "Environmental photocatalysis," International Journal of Photoenergy, vol. 2012, Article ID 594214, 4 pages, 2012.

[7] Q. Y. Chen and D. Ma, "Preparation of nanostructured $\mathrm{Cu}_{2} \mathrm{SnS}_{3}$ photocatalysts by solvothermal method," International Journal of Photoenergy, vol. 2013, Article ID 593420, 5 pages, 2013.

[8] X. C. Wang, S. Blechert, and M. Antonietti, "Polymeric graphitic carbon nitride for heterogeneous photocatalysis," ACS Catalysis, vol. 2, no. 8, pp. 1596-1606, 2012.

[9] Y. J. Cui, Z. X. Ding, X. Z. Fu, and X. C. Wang, "Construction of conjugated carbon nitride nanoarchitectures in solution at low temperatures for photoredox catalysis," Angewandte Chemie, vol. 51, no. 47, pp. 11814-11818, 2012.

[10] G. Liu, P. Niu, and H. M. Cheng, "Visible-light-active elemental photocatalysts," ChemPhysChem, vol. 14, no. 5, pp. 885-892, 2013.

[11] Y. Wang, X. C. Wang, and M. Antonietti, "Polymeric graphitic carbon nitride as a heterogeneous organocatalyst: from photochemistry to multipurpose catalysis to sustainable chemistry," Angewandte Chemie, vol. 51, no. 1, pp. 68-89, 2012.

[12] Z. Z. Lin and X. C. Wang, "Nanostructure engineering and doping of conjugated carbon nitride semiconductors for hydrogen photosynthesis," Angewandte Chemie, vol. 52, no. 6, pp. 17351738, 2013.

[13] G. Xin and Y. L. Meng, "Pyrolysis synthesized g- $\mathrm{C}_{3} \mathrm{~N}_{4}$ for photocatalytic degradation of methylene blue," Journal of Chemistry, vol. 2013, Article ID 187912, 5 pages, 2013.

[14] J. D. Hong, X. Y. Xia, Y. S. Wang, and R. Xu, "Mesoporous carbon nitride with in situ sulfur doping for enhanced photocatalytic hydrogen evolution from water under visible light," Journal of Materials Chemistry, vol. 22, no. 30, pp. 15006-15012, 2012.

[15] G. P. Mane, D. S. Dhawale, C. Anand et al., "Selective sensing performance of mesoporous carbon nitride with a highly ordered porous structure prepared from 3-amino-1,2,4-triazine," Journal of Materials Chemistry A, vol. 1, no. 8, pp. 2913-2920, 2013. 
[16] http://en.wikipedia.org/wiki/MainPage.

[17] X. H. Li, X. C. Wang, and M. Antonietti, "Mesoporous g$\mathrm{C}_{3} \mathrm{~N}_{4}$ nanorods as multifunctional supports of ultrafine metal nanoparticles: hydrogen generation from water and reduction of nitrophenol with tandem catalysis in one step," Chemical Science, vol. 3, no. 6, pp. 2170-2174, 2012.

[18] B. Kiskan, J. S. Zhang, X. C. Wang, M. Antonietti, and Y. Yagci, "Mesoporous graphitic carbon nitride as a heterogeneous visible light photoinitiator for radical polymerization," ACS Macro Letters, vol. 1, no. 5, pp. 546-549, 2012.

[19] M. Shalom, S. Inal, C. Fettkenhauer, D. Neher, and M. Antonietti, "Improving carbon nitride photocatalysis by supramolecular preorganization of monomers," Journal of the American Chemical Society, vol. 135, no. 19, pp. 7118-7121, 2013.

[20] F. Dong, L. W. Wu, Y. J. Sun, M. Fu, Z. B. Wu, and S. C. Lee, "Efficient synthesis of polymeric $\mathrm{g}-\mathrm{C}_{3} \mathrm{~N}_{4}$ layered materials as novel efficient visible light driven photocatalysts," Journal of Materials Chemistry, vol. 21, no. 39, pp. 15171-15174, 2011.

[21] F. Dong, Y. J. Sun, L. W. Wu, M. Fu, and Z. B. Wu, "Facile transformation of low cost thiourea into nitrogen-rich graphitic carbon nitride nanocatalyst with high visible light photocatalytic performance," Catalysis Science \& Technology, vol. 2, no. 7, pp. 1332-1335, 2012.

[22] S. C. Yan, Z. S. Li, and Z. G. Zou, "Photodegradation performance of $\mathrm{g}-\mathrm{C}_{3} \mathrm{~N}_{4}$ fabricated by directly heating melamine," Langmuir, vol. 25, no. 17, pp. 10397-10401, 2009.

[23] H. Xu, J. Yan, Y. G. Xu et al., "Novel visible-light-driven AgX/graphite-like $\mathrm{C}_{3} \mathrm{~N}_{4}(\mathrm{X}=\mathrm{Br}, \mathrm{I})$ hybrid materials with synergistic photocatalytic activity," Applied Catalysis B, vol. 129, pp. 182-193, 2013.

[24] A. Vinu, "Two-dimensional hexagonally-ordered mesoporous carbon nitrides with tunable pore diameter, surface area and nitrogen content," Advanced Functional Materials, vol. 18, no. 5, pp. 816-827, 2008.

[25] A. Vinu, K. Ariga, T. Mori et al., "Preparation and characterization of well-ordered hexagonal mesoporous carbon nitride," Advanced Materials, vol. 17, no. 13, pp. 1648-1652, 2005.

[26] A. Vinu, P. Srinivasu, D. P. Sawant et al., "Three-dimensional cage type mesoporous $\mathrm{CN}$-based hybrid material with very high surface area and pore volume," Chemistry of Materials, vol. 19, no. 17, pp. 4367-4372, 2007.

[27] X. G. Ma, Y. H. Lv, J. Xu, Y. F. Liu, R. Q. Zhang, and Y. F. Zhu, "A strategy of enhancing the photoactivity of $\mathrm{g}-\mathrm{C}_{3} \mathrm{~N}_{4}$ via doping of nonmetal elements: a first-principles study," The Journal of Physical Chemistry C, vol. 116, no. 44, pp. 23485-23493, 2012.

[28] J. Gracia and P. Kroll, "First principles study of $\mathrm{C}_{3} \mathrm{~N}_{4}$ carbon nitride nanotubes," Journal of Materials Chemistry, vol. 19, no. 19, pp. 3020-3026, 2009.

[29] F. Goettmann, A. Fischer, M. Antonietti, and A. Thomas, "Chemical synthesis of mesoporous carbon nitrides using hard templates and their use as a metal-free catalyst for Friedel-Crafts reaction of benzene," Angewandte Chemie, vol. 45, no. 27, pp. 4467-4471, 2006.

[30] Y. Zhang, Z. M. Pan, and X. C. Wang, "Advances in photocatalysis in China," Chinese Journal of Catalysis, vol. 34, no. 3, pp. 524-535, 2013.

[31] V. N. Khabashesku, J. L. Zimmerman, and J. L. Margrave, "Powder synthesis and characterization of amorphous carbon nitride," Chemistry of Materials, vol. 12, no. 11, pp. 3264-3270, 2000 .
[32] G. G. Zhang, J. S. Zhang, M. W. Zhang, and X. C. Wang, "Polycondensation of thiourea into carbon nitride semiconductors as visible light photocatalysts," Journal of Materials Chemistry, vol. 22, no. 16, pp. 8083-8091, 2012.

[33] Y. Ham, K. Maeda, D. Cha, K. Takanabe, and K. Domen, "Synthesis and photocatalytic activity of poly (triazine imide)," Chemistry, vol. 8, no. 1, pp. 218-224, 2013.

[34] Y. J. Cui, J. S. Zhang, G. G. Zhang et al., "Synthesis of bulk and nanoporous carbon nitride polymers from ammonium thiocyanate for photocatalytic hydrogen evolution," Journal of Materials Chemistry, vol. 21, no. 34, pp. 13032-13039, 2011.

[35] Y. W. Zhang, J. H. Liu, G. Wu, and W. Chen, "Porous graphitic carbon nitride synthesized via direct polymerization of urea for efficient sunlight-driven photocatalytic hydrogen production," Nanoscale, vol. 4, no. 17, pp. 5300-5303, 2012.

[36] S. Wang, Q. Y. Gao, and J. C. Wang, "Thermodynamic analysis of decomposition of thiourea and thiourea oxides," The Journal of Physical Chemistry B, vol. 109, no. 36, pp. 17281-17289, 2005.

[37] J. Xu, H. T. Wu, X. Wang, B. Xue, Y. X. Li, and Y. Cao, "A new and environmentally benign precursor for the synthesis of mesoporous $\mathrm{g}_{-} \mathrm{C}_{3} \mathrm{~N}_{4}$ with tunable surface area," Physical Chemistry Chemical Physics, vol. 15, no. 13, pp. 4510-4517, 2013.

[38] M. Sadhukhan and S. Barman, "Bottom-up fabrication of twodimensional carbon nitride and highly sensitive electrochemical sensors for mercuric ions," Journal of Materials Chemistry A, vol. 1, no. 8, pp. 2752-2756, 2013.

[39] H. T. Tian, J. W. Li, M. Ge, Y. P. Zhao, and L. Liu, "Removal of bisphenol a by mesoporous $\mathrm{BiOBr}$ under simulated solar light irradiation," Catalysis Science \& Technology, vol. 2, no. 11, pp. 2351-2355, 2012.

[40] J. S. Zhang, X. F. Chen, K. Takanabe et al., "Synthesis of a carbon nitride structure for visible-light catalysis by copolymerization," Angewandte Chemie, vol. 49, no. 2, pp. 441-444, 2010.

[41] J. H. Li, B. Shen, Z. H. Hong, B. Z. Lin, B. F. Gao, and Y. L. Chen, "A facile approach to synthesize novel oxygen-doped g- $\mathrm{C}_{3} \mathrm{~N}_{4}$ with superior visible-light photoreactivity," Chemical Communications, vol. 48, no. 98, pp. 12017-12019, 2012. 

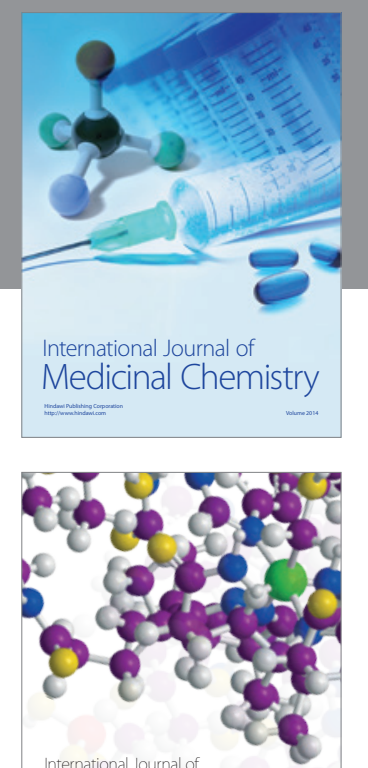

\section{Carbohydrate} Chemistry

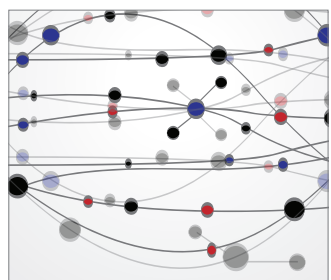

The Scientific World Journal
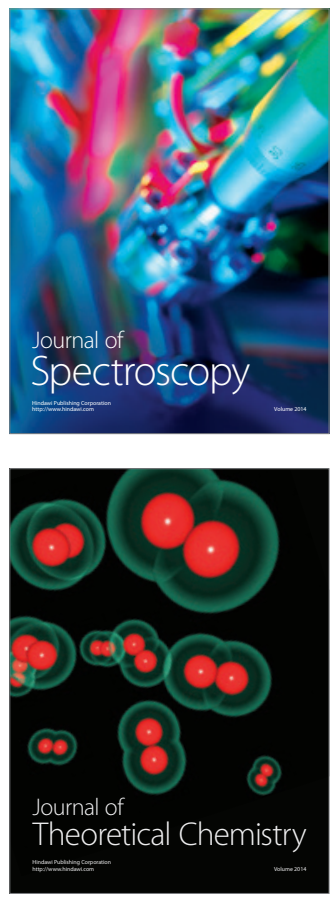
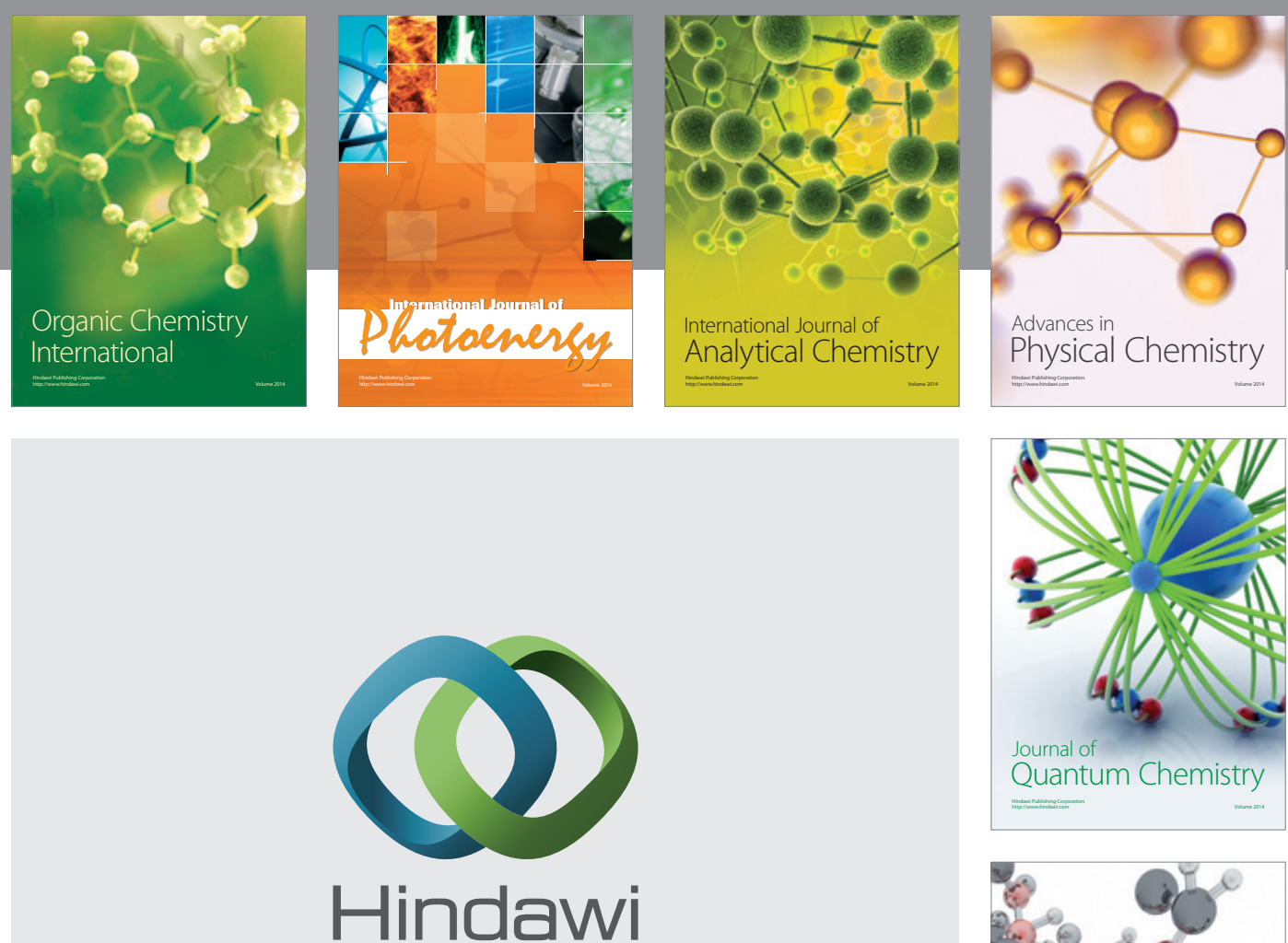

Submit your manuscripts at

http://www.hindawi.com

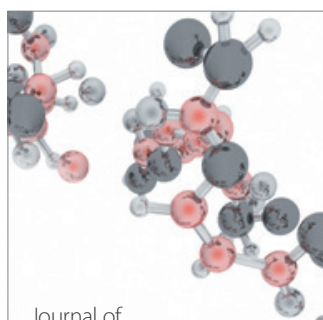

Analytical Methods

in Chemistry

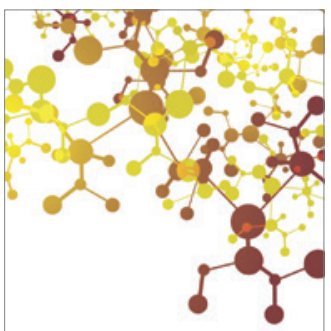

Journal of

Applied Chemistry

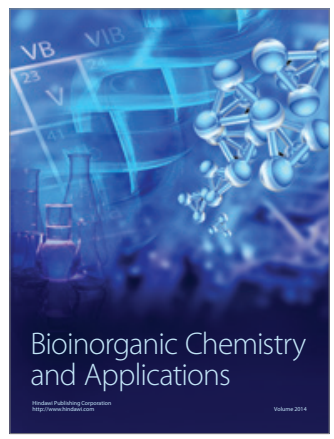

Inorganic Chemistry
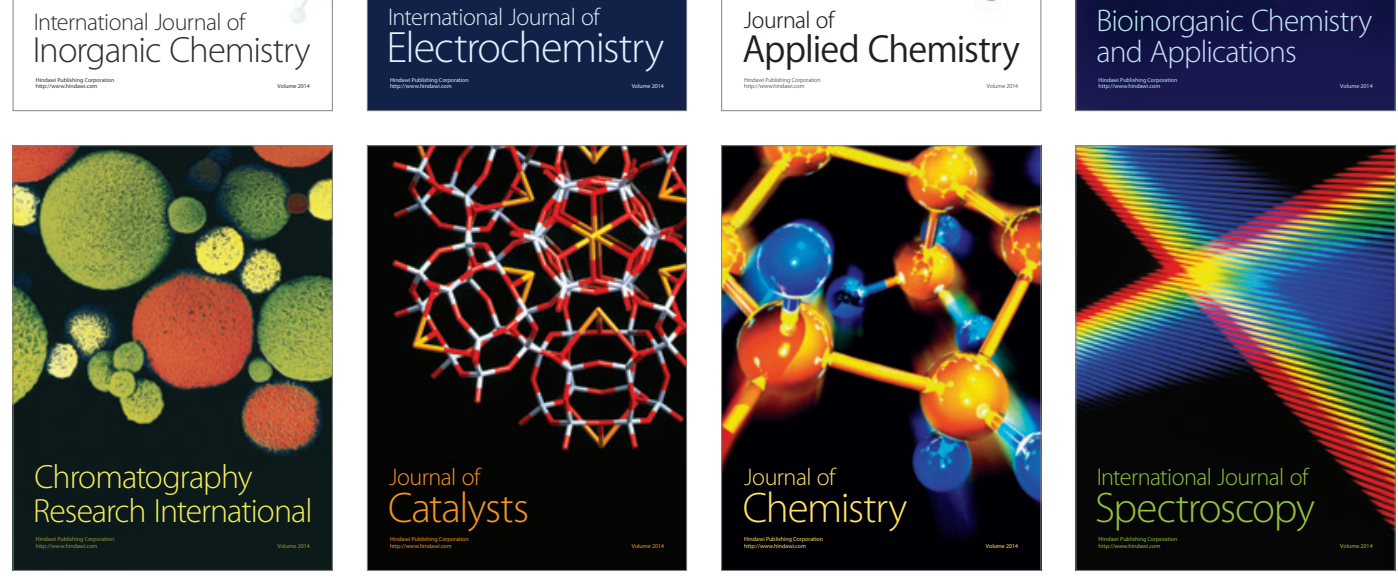